\title{
Ion partitioning and element mobilization during mineral replacement reactions in natural and experimental systems
}

\author{
Christine V. PUTNIS ${ }^{1, *}$ and LURDES FERNÁNDEZ DÍAZ ${ }^{2}$ \\ ${ }^{1}$ Institute of Mineralogy, University of Münster, Corrensstrasse 24, 48149 Münster, \\ Germany,e-mail:putnisc@uni-muenster.de \\ ${ }^{2}$ Department of Crystallography and Mineralogy, Complutense University of Madrid, \\ C/ José Antonio Novais, 2, 28040 Madrid, Spain \\ *Corresponding author
}

\begin{abstract}
Mineral replacement is a common phenomenon in a wide range of geological environments. Metasomatism, metamorphism, weathering, diagenesis and fossilization are examples of processes that can involve the replacement of one or more minerals associated with extensive chemical change. Such replacements are very often pseudomorphic. At relatively low temperatures such as those at the surface or within the upper part of the Earth's crust, where solid-state diffusion can be considered negligible, mineral replacement is the result of interface-coupled dissolution-precipitation reactions, driven by the interplay between the degrees of saturation of natural fluids with respect to different mineral phases. These reactions can play an important role in the mobilization and partitioning of elements. Mineral replacement is accompanied by the generation of porosity, which provides a pathway for the penetration of the fluid within the original parent mineral and facilitates mass transport. This chapter highlights the importance of dissolution-precipitation mineral replacements for element mobilization and ion partitioning in the Earth by presenting and discussing both experimental models and examples of natural processes, development of which can involve significant chemical change, such as during serpentinization and bone fossilization.
\end{abstract}

\section{Introduction}

Whenever minerals are in contact with aqueous fluids, reactions take place in an attempt to reach a new equilibrium. Aqueous fluids are ubiquitous in the crust of the Earth and so minerals are constantly re-equilibrating. There are several possibilities for this equilibration:

(1) The mineral may dissolve into the fluid phase. If the resultant fluid is undersaturated with respect to all possible mineral phases, the mineral will continue to dissolve, e.g. this occurs extensively during limestone weathering to result in holes and caves in the rock.

(2) However, if the fluid becomes supersaturated with respect to another mineral phase, then this mineral may precipitate, e.g. the infilling of veins with phases, such as quartz, calcite, zeolites, different from the parent rock. 
fluid, coupled with precipitation of a new solid phase. The main features of such a coupled dissolution-precipitation mechanism are:

(1) the dissolution of the parent solid in a fluid layer at the mineral interface, such that this boundary fluid layer becomes saturated with respect to another phase (or phases), which can then immediately/simultaneously precipitate as the new product solid mineral phase;

(2) the generation of porosity in the product phase which is less soluble in the fluid at the interface than the parent phase;

(3) the movement of the fluid phase through the generated porosity within the product up to the interface between parent and product minerals.

The replacement reaction takes place at an interface that moves continuously within the mineral. The rate of replacement depends on the rates of dissolution and precipitation as well as the diffusion of elements within the aqueous fluid to and from the reaction interface. Porosity provides a pathway for mass transport and hence, element mobilization.

The main observation is that by a careful analysis of textural and compositional characteristics, valuable information about the past history of a mineral can be collected, as well as elucidating possible element exchanges between solid mineral and aqueous fluid phases. As soon as minerals form or crystallize in a given environment of temperature, pressure and chemistry, they begin to undergo changes or re-equilibrate in response to changes in the physical and chemical surrounding conditions. The examples illustrated here show that it is possible to retain external form and crystallographic information, while the chemical composition is completely changed, that is, a pseudomorphic replacement. During this process elements may be mobilized into solution while others are precipitated from solution into a new mineral replacement. Therefore coupled dissolution-precipitation is a mechanism whereby element mobilization effectively partitions elements into new mineral phases. This mechanism is likely to be relevant in the Earth whenever one mineral is pseudomorphically replaced by another.

\section{Acknowledgements}

The authors are grateful for funding received from various sources, enabling much of the research reported here to be carried out. CVP acknowledges support from Marie Curie Initial Training networks, MIR (Contract No. MEST-CT-2005-021120), MinGro (Contract No. MRTN-CT-2006-035488) and DeltaMin (Contract No. PITN-GA-2008215360) and the German Research Council (DFG), as well as the support from the technical staff at the Institut für Mineralogie, Münster. LFD acknowledges support from the Spanish Ministry of Science and Innovation (Project CGL2007-65523-C02-01) and the Comunidad de Madrid (Project CAM-2009 910148), as well as the assistance and support from technical staff at the Central Services (Microscopy Centre and Diffraction Centre) of the Universidad Complutense de Madrid. 
Wicks, F.J. \& Whittaker, E.J.W. (1977) Serpentine textures and serpentinization, The Canadian Mineralogist, 15, 459-488.

Wigley, T.M.L. (1973) Chemical evolution of the system calcite-gypsum-water. Canadian Journal of Earth Sciences, 10, 306-315.

Williams, C.T. (1988) Alteration of chemical composition of fossil bones by soil processes and groundwater. In: Trace Elements in Environmental History (G. Grupe \& B. Herrmann, editors), 27-40. SpringerVerlag, Berlin.

Williams, C.T. \& Marlow, C.A. (1987) Uranium and Thorium distributions in fossil bones from Olduvai Gorge,Tanzania and Kanam, Kenya. Journal of Archaeological Science, 14, 297-309.

Xia, F. Zhou, J., Brugger, J., Ngothai, Y., O’Neill, B., Chen, G. \& Pring, A. (2008) Novel route to synthesise complex metal sulphides: Hydrothermal coupled dissolution-reprecipiation reactions. Chemistry of Materials, 20, 2808-2817.

Xia, F. Brugger, J., Ngothai, Y., O’Neill, B., Chen, G. \& Pring, A. (2009) Three-dimensional ordered arrays of zeolite nanocrystals with uniform size and orientation by a pseudomorphic coupled dissolutionreprecipitation replacement route. Crystal Growth and Design, 9, 4902-4906.

Yanagisawa, K., Rendón-Ángeles, J.C., Ishiwara, N. \& Oishi, S. (1999) Topotaxial replacement of chlorapatite by hydroxyapatite during hydrothermal ion exchange. American Mineralogist, 84, 1861-1869.

Zocco, T.G. \& Schwartz, H.L. (1994) Microstructural analysis of bone of the sauropod dinosaur Seismosaurus by transmission electron microscopy. Palaeontology 37, 493-503. 